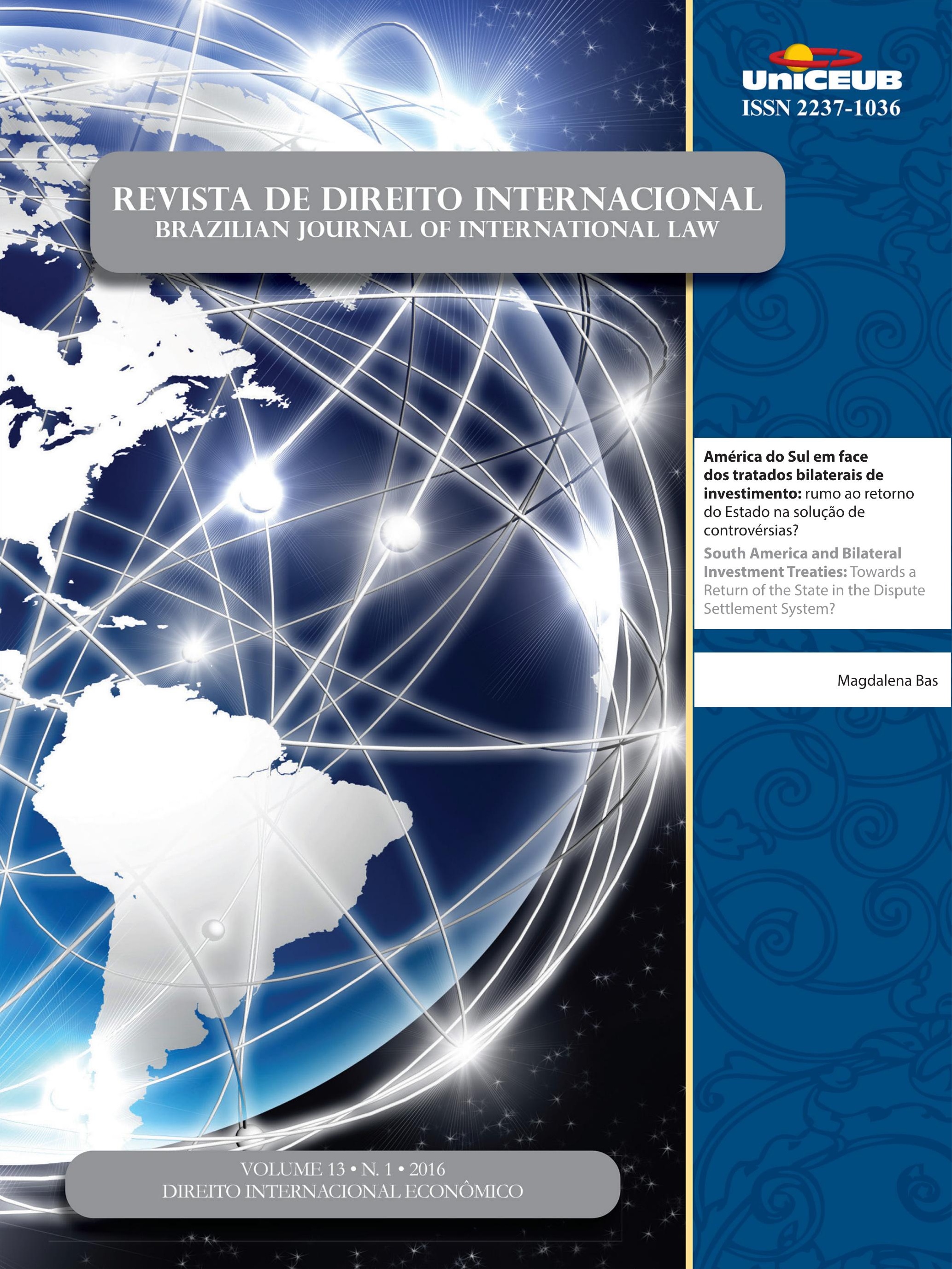




\section{Sumário}

Dossiê Temático: Direito Internacional Econômico.........................................................1

EDITORIAL:

Resultados da III Conferência Bienal da Red DEI ................................................. 3

Michelle Ratton Sanchez-Badin (em nome da Diretoria da Red DEI), Fabio Costa Morosini e Lucas da Silva Tasquetto (em nome dos organizadores da III Conferência da Red DEI)

Direito Internacional Econômico no Brasil: QUem Somos E o QUE faZemos? EvidênCIas EMPÍRICAS DE 1994 A 2014

Michelle Ratton Sanchez Badin, Fabio Costa Morosini e Inaê Siqueira de Oliveira

UM ESPAÇO PARA PENSAR EM ALTERNATIVAS? A ACADEMIA LATINO-AMERICANA DE DIREITO INTERNACIONAL ECONÔMICO FRENTE À ORDEM ECONÔMICA GLOBAL

Nicolás Marcelo Perrone

Grupo de alto Nível Brasil - Urugua (GAN): um Novo paradigma para a INTEgraÇão PRODUTIVA NO MERCOSUL

Alebe Linhares Mesquita e Vivian Daniele Rocha Gabriel

O COMÉRCIO de SERVIÇOS ENTRE Brasil E URUGUAI: LiberalizaÇÃo, DESAFIOS E PERSPECTIVAS DO SETOR DE TECNOLOGIA DA INFORMAÇÃO E COMUNICAÇÃO (TIC) E SOFTWARES

Vivian Daniele Rocha Gabriel e Alebe Linhares Mesquita

Core Labor Standards No Regime de PREFERÊNCIAS TARIFÁrias No MERCOSUL: A NeCESSIDADE DE HUMANIZAÇÃO DO COMÉRCIO INTERNACIONAL

Martinho Martins Botelho e Marco Antônio César Villatore

ACordo TRIMS: FleXibilizaÇão ou Não? Política de CONTEÚdo loCal, PROCESSO PROdUTIVO BÁSICO (PPB) E OS DESAFIOS PARA A INDÚSTRIA BRASILEIRA E A INTEGRAÇÃo LATINO-AMERICANA 100

Natália Figueiredo 
ESTUDIOS DE CASO DE RECHAZOS EN FRONTERA DE EXPORTACIONES ALIMENTARIAS LATINOAMERICANAS POR MOTIVOS RELACIONADOS CON MEDIDAS TÉCNICAS NO ARANCELARIAS.

Sofía Boza, Juan Rozas e Rodolfo Rivers

América do Sul em face dos tratados bilaterais de inVESTimento: RUMO aO RETORNo do EsTADO NA SOLUÇão DE CONTROvÉRSIAS? 133 Magdalena Bas

FutURo DE LOS SISTEMAS NACIONALES DE CIENCIA TECNOLOGÍA E INNOVACIÓN EN LA AGENDA ECONÓMICA DE AMÉRICA LATINA: DEFINIENDO CAMBIOS REGULATORIOS O PROTEGIENDO INVERSIONES 146

Rodrigo Corredor

EL PAPEL DE LAS INSTITUCIONES DE CONTROL FINANCIERO SOBRE LOS DERECHOS HUMANOS EN EL CONTEXTO LATINOAMERICANO 157 Jose Miguel Camacho Castro

CONVERGENCIA REgUlATORIA EN LA ALIANZA DEL PACÍFICO: UN CAPÍTULO INCONCLUSO 170 Rodrigo Polanco Lazo

O CONSTITUCIONALISMO E A COMUNITARIZAÇÃO NO DIREITO INTERNACIONAL: POSSIBILIDADES PARA O COMÉRCIO INTERNACIONAL?

Camilla Capucio

ESCASSEZ HÍDRICA E DIREITO INTERNACIONAL ECONÔMICO: O BRASIL COMO PROTAGONISTA NA TRANSFERÊNCIA DE ÁGUA PARA REGIÕES ÁRIDAS

Douglas de Castro

A Segurança energética como base para maior integração na América Do Sul: à espera DE UM TRATADO MULTILATERAL

Matheus Bassani

Outros Artigos. 246

As PRÁtICAS RESTRITIVAS DA CONCORRÊNCIA NO MERCADO DE CONTRATAÇÃo PÚBLICA EUROPEU .. 248 Alice Rocha da Silva e Ruth M. P. Santos 
Do TRANSNACIONAL PARA O NACIONAL: IOSCO, O MERCADO DE VALORES MOBILIÁRIOS BRASILEIRO E ACCOUNTABILITY

Salem Nasser, Nora Rachman e Viviane Muller Prado

MigRaÇÃo de TRABALHADORES INTELECTUAIS BRASILEIROS PARA O MERCADO INTERNACIONAL: IDENTIFICAÇÃO DE ATOS DE ALICIAMENTO DE EMPREGADOS E MECANISMOS LEGAIS PARA IMPEDIR A APROPRIAÇÃo TECNOLÓGICA E CONCORRÊNCIA DESLEAL ..........................................285 José Carlos Vaz e Dias e João Marcelo Sant'Anna da Costa

THE EASIER WAY TO HAVE "BETTER LAW"? THE MOST-SIGNIFICANT-RELATIONSHIP DOCTRINE AS THE FALLBACK CONFLICT-OF-LAW RULE IN THE PEOPLE'S REPUBLIC OF CHINA

Chi Chung

REFLEXOS JURÍDiCOS DA GOVERNANÇA GLOBAL SUBNACIONAL: A PARADIPLOMACIA E O DIREITO INTERNACIONAL: DESAFIO OU ACOMODAÇÃO 320

Valéria Cristina Farias e Fernando Rei

Matrizes Políticas da JUSTiÇA PENAL INTERNACIONAL. 341 Francisco Rezek

RESPONSABILIDAD INTERNACIONAL DEL ESTADO FRENTE A LUCHA CONTRA LA DISCRIMINACIÓN RACIAL Y ÉTNICA EN ESPAÑA. 348

Edilney Tomé da Mata e Eduardo Biacchi Gomes Correio

The Peace Process in Sierra Leone: an analysis on marriages between culture and CRIME

Gustavo Bussmann Ferreira

Funcionalização e expansão do Direito Penal: o Direito Penal negocial ...............376 Antonio Henrique Graciano Suxberger e Dermeval Farias Gomes Filho

Proteção Internacional do Consumidor e Cooperação Interjurisdicional .396 Héctor Valverde Santana e Sophia Martini Vial

The land rights of indigenous and traditional peoples in Brazil and Australia.... 418 Márcia Dieguez Leuzinger e Kylie Lyngard 
The reception of European ideas in Latin America: the issue of the German sources in Tobias Barreto, A Prominent nineteenth CENTURy BraZilian legal scholar........439 Arnaldo Sampaio de Moraes Godoy

Normas Editoriais ..................................................................................... 461 


\title{
América do Sul em face dos tratados bilaterais de investimento: rumo ao retorno do Estado na solução de controvérsias?*
}

\author{
South America and Bilateral Investment \\ Treaties: Towards a Return of the State in the \\ Dispute Settlement System?
}

Magdalena Bas**

\section{Resumo}

Este trabalho, parte integrante de uma pesquisa financiada pela Comissão Setorial de Pesquisa Científica (Universidad de la República, Uruguai), busca contribuir para o debate sobre os mecanismos de solução de controvérsias investidor-Estado baseados, especialmente, nos tratados bilaterais de investimento (TBIs) e o Centro Internacional de Solução de Controvérsias Relativas a Investimento (ICSID) (sistema TBIs-ICSID) (1965). O artigo tem por escopo: 1) sistematizar os TBIs em vigor em Estados sul-americanos, salvo exceções, conforme os mecanismos de solução de controvérsias investidor-Estado; 2) examinar as posições estatais sobre a matéria mediante a construção de uma tipologia de Estados, enquadrada na teoria dos regimes internacionais. Metodologicamente opta-se por uma abordagem jurídico-descritiva com o intuito de abranger as três dimensões do Direito: normas, fatos e valores. Toma-se como universo de estudo os 275 TBIs em vigor até 2015, salvo as exceções da Bolívia, Equador, Venezuela e Brasil para os quais estão incluídos tanto os acordos em vigor quanto os concluídos e/ou celebrados. Complementa-se com uma análise da doutrina e jurisprudência, e entrevistas a informantes qualificados dos âmbitos acadêmico, social e governamental. Como principal resultado, destaca-se que a arbitragem ad hoc no ICSID é o principal mecanismo previsto no universo de acordos estudados e que existem três tipos de Estados sul-americanos conforme sua posição a respeito do sistema TBIs-ICSID: os membros (Argentina, Colômbia, Chile, Guiana, Paraguai, Peru, Suriname e Uruguai), os externos (Brasil) e os dissidentes (Bolívia, Equador e Venezuela).

Palavras-chave: Tratados bilaterais de investimento. Solução de controvérsias. América do Sul.

* Recebido em 23/03/2016 Aprovado em 07/06/2016

** Professora e pesquisadora em Direito Internacional Público da Universidad de la República, Uruguai. Professora de Direito do Comércio Internacional da Universidad de Montevideo, Uruguai. Membro da Rede Latino-Americana de Direito Econômico Internacional e da Rede Internacional de Juristas para a Integração Americana.E-mail:magdalenabas@gmail.com

\section{Abstract}

This paper, that is part of a research funded by the Sectorial Commission of Scientific Research (Universidad de la República, Uruguay), seeks to contribute to the debate around investor-State dispute settlement (ISDS), based specially on the bilateral investment treaties (BITs) and the Washing- 
ton Convention (1965) that establishes the International Centre for Settlement on Investment Disputes (ICSID) (BITs-ICSID system). The specific objectives of this paper are: 1) to systematize the bilateral investment treaties in force in South American States, with some exceptions, by ISDS mechanisms; 2) to examine the States position around BITs-ICSID system, by the construction of a typology of States within the international regimes theory. Methodologically, it is employed a legal-descriptive approach, in order to cover the three dimensions of Law: norms, facts and values. The universe of study is composed by 275 BITs that are in force in 2015 in South America, with the exceptions of the Bolivian, Ecuadorian, Venezuelan and Brazilian case which include the treaties that are in force, terminated and/or signed. The research is complemented with an analysis of doctrine and jurisprudence, and interviews to academic, social and governmental specialists. Among the preliminary results, it could be remarked that the ICSID ad hoc arbitration is the principal mechanism included in the agreements studied, and there are three types of South American States regarding their position around BITs-ICSID system: the members (Argentina, Colombia, Chile, Guyana, Paraguay, Peru, Suriname and Uruguay), the outsiders (Brazil) and the dissidents (Bolivia, Ecuador and Venezuela).

Keywords: Bilateral investment treaties. Dispute settlement. South America.

\section{INTRODUÇÃo}

Para regular suas relações externas, os Estados criaram um sistema jurídico de coordenação, o Direito Internacional Público, que contribui para a preservação de sua soberania, atributo jurídico que os Estados se reconhecem reciprocamente e de forma excludente de qualquer outro tipo de organização. Nos últimos anos, a comunidade internacional tem sido testemunha da fragmentação desse sistema jurídico em diferentes regimes autocontidos (self-contained regimes), produto da diversificação do elenco de matérias suscetíveis de serem reguladas internacionalmente ${ }^{1} \mathrm{e}$ da prerrogativa dos Estados

1 ORGANIZAÇÃO DAS NAÇÕES UNIDAS. Fragmentación del Derecho Internacional: dificultades derivadas de la diversificación y expansión del Derecho Internacional. Anuario de la Comisión de Derecho Internacional, $58^{a}$ período de sesiones, p. 192-202, Nova Iorque. Disponível em: <http://legal.un.org/docs/index.asp?path=../ilc/re- de ser parte ou não de tratados internacionais ${ }^{2}$.

Estes são espaços de regulação especiais que contam com regras, valores, princípios e inclusive fontes jurídicas próprias ${ }^{3}$, os quais não necessariamente são compartilhados com o Direito Internacional Geral ou outros regimes autocontidos. $\mathrm{Na}$ esteira dos teóricos das relações internacionais que introduziram o conceito de regimes internacionais no referido âmbito de estudo, os princípios, normas e regras estabelecem ações, proibições e obrigações, formando o arcabouço dentro do qual acontece a interação entre atores e condiciona-se a tomada de decisões, individuais e conjuntas, conforme a conduta esperada dos outros membros ${ }^{4}$.

É o caso do Direito Internacional dos Investimentos, baseado principalmente nos tratados bilaterais de investimento e na Convenção de Washington que cria o Centro Internacional de Solução de Controvérsias relativas a Investimento (ICSID) (sistema TBIs-ICSID). Dentro de suas particularidades, entre outras características, destacam-se: a arbitragem ad hoc para a solução de controvérsias entre investidores estrangeiros e Estados cujos laudos são inapeláveis; a ausência, em alto número de casos, do requisito de esgotamento da jurisdição doméstica como condição prévia para o início da arbitragem internacional; a incorporação de cláusulas de ultratividade que prorrogam a vigência de parte do articulado dos tratados ainda depois de seu término.

Nesse contexto, o presente trabalho tem como objetivo geral contribuir para o debate sobre os mecanismos de solução de controvérsias investidor-Estado no Direito Internacional atual. Com esse escopo, o artigo estrutura-se em duas partes. Em primeiro lugar, proceder-se-á a apresentar os resultados de uma sistematiza-

ports/2006/spanish/chp12.pdf\&lang=EFSRAC\&referer=http:// legal.un.org/ilc/reports/2006/>. Acesso em: 28 fev. 2016

2 NASSER, Salem Hikmat. Direito Global em pedaços: fragmentação, regimes e pluralismo. Revista de Direito Internacional, Brasília, v. 12, n. 2, p. 98-126, 2015. p. 114.

3 LIMA, Gabriela Garcia Batista. Conceitos de relações internacionais e teoria do direito diante dos efeitos pluralistas da globalização: governança global, regimes jurídicos, direito reflexivo, pluralismo jurídico, corregulação e autorregulação. Revista de Direito Internacional, Brasília, v. 11, n. 1, p. 215-228, 2014.

4 KRASNER, Stephen. Structural causes and regime consequences: regimes as intervening variables. In: KRASNER, Stephen (Ed.). International regimes. Ithaca: Cornell University Press, 1983. p. 2. RUGGIE, John. International Responses to Technology: Concepts and Trends. International Organization, Cambridge, v. 3, n. 29, p. 557-583, 1975. Disponível em: <http://www.jstor.org/stable/2706342>. Acesso em: 12 out. 2015. 
ção dos tratados bilaterais de investimento em vigor em Estados sul-americanos, salvo as exceções da Bolívia, Equador, Venezuela e Brasil para os quais estão incluídos tanto os acordos em vigor quanto os concluídos e/ ou celebrados, segundo os mecanismos de solução de controvérsias investidor-Estado.

Em segundo lugar, proceder-se-á ao exame das posições estatais que têm se manifestado na América do Sul. Para esse último ponto, propõe-se uma tipologia de Estados, enquadrada na Teoria dos Regimes Internacionais, baseada na posição destes relativamente ao sistema TBIs-ICSID: os membros (Argentina, Chile, Colômbia, Guiana, Paraguai, Peru, Suriname e Uruguai), os externos (Brasil) e os dissidentes (Bolívia, Equador, Venezuela).

Finalmente, o artigo encerra com uma série de conclusões em relação as duas áreas sob análise e com algumas reflexões sobre as perspectivas de futuro.

\section{SOLUÇÃo de CONTROVÉRSIAS INVESTIDOR- ESTADO NOS TRATADOS BILATERAIS DE inVESTIMENTO dA AMÉRICA do SUL}

Fundamentados na doutrina Calvo, na reunião anual da Junta de Governadores do Banco Mundial em setembro de 1964 em Tóquio, uma série de Estados latino-americanos (Argentina, Bolívia, Brasil, Chile, Colômbia, Costa Rica, República Dominicana, Equador, El Salvador, Guatemala, Haiti, Honduras, México, Nicarágua, Panamá, Paraguai, Peru, Uruguai e Venezuela ${ }^{5}$ ), juntamente ao Iraque e Filipinas, votaram contra o esboço preliminar da Convenção de Washington. O texto final foi aprovado em 1965 e entrou em vigor em 1966. Esse fato é conhecido como "Tokyo no", situação que, nos anos posteriores, se reverte.

Nesse sentido, a década de noventa representa o momento de auge de assinatura e ratificação de TBIs e

5 BOEGLIN, Nicolás. Ecuador y el CIADI: nuevo pulso con posibles repercusiones. 2012. Disponível em: < http://alainet.org/active/58693 >. Acesso em: 23 jan. 2015

6 FACH, Katia. Latin America and ICSID: David versus Goliath? p. 2. Disponível em: <http://ssrn.com/abstract $=1708325>$. Acesso em: 14 dez. 2014.; SCHREUER, Christoph. The ICSID Convention: A Commentary. 2. ed. Cambridge: Cambridge University Press, 2009. p. 2-3; BOEGLIN, Nicolás. Ecuador y el CLADI: nuevo pulso con posibles repercusiones. 2012. Disponível em: <http://alainet.org/ active/58693>. Acesso em: 23 jan. 2015. adesão à Convenção de Washington 7 na América do Sul. Geraram um clima favorável a isso as reformas estruturais do consenso de Washington promovidas pelas organizações econômicas internacionais, que impulsionaram medidas de desregulação do mercado, privatização de serviços públicos e liberalização de barreiras ao investimento estrangeiro direto, bem como o fracasso de propostas multilaterais de proteção de investimentos ${ }^{8}$. Em relação aos 275 acordos examinados, pouco mais de $80 \%$ foram assinados na década de 90 (ver gráfico 1).

Gráfico 1 - TBIs na América do Sul assinados na década de 90

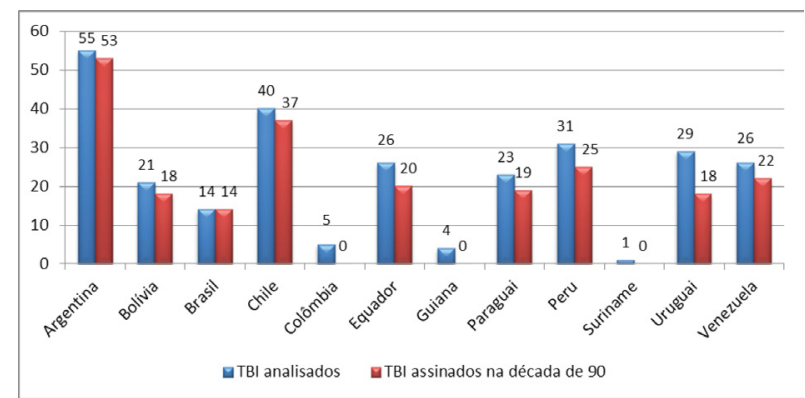

Fonte: Elaboração própria com base nos acordos

Os TBI assinados seguem os padrões gerais, contendo disposições que regulam diversas áreas que podem agrupar-se em: 1) Normas gerais de tratamento do investimento: alcance e definição de investimento, tratamento nacional, cláusula da nação mais favorecida, tratamento justo e equitativo. 2) Proteção aos investimentos: garantias e compensações por expropriação, garantias de livre repasse de fundos e transferência de capitais e rendimentos ao exterior, proibição ou limites aos requisitos de desempenho. 3) Exceções, modificações e término do tratado. 4) Solução de controvérsias: mecanismos de solução de controvérsias Estado-Estado e investidor-Estado?.

7 São parte a Argentina, Chile, Colômbia, Guiana, Paraguai, Peru e Uruguai. Bolívia, Equador e Venezuela denunciaram-no.

8 FERNANDEZ, José. Controvérsias entre Estados e investidores transnacionais: reflexões sobre o acúmulo de casos contra a República Argentina. Revista Tempo do mundo, Brasília, v. 5, n. 1, p. 4587, abr. 2013. Disponível em: <http://www.ipea.gov.br/portal/ images/stories/PDFs/rtm/140903_rtmv5_n1_port_cap2.pdf>. Acesso em: 12 nov. 2014; BOHOSLAVSKY, Juan Pablo. Tratados de protección de las inversiones e implicaciones para la formulación de politicas públicas (especial referencia a los servicios de agua potable y saneamiento). Santiago: Comisión Económica para América Latina y el Caribe (CEPAL), 2010. p. 18; COSTA, José Augusto Fontoura. Direito Internacional do Investimento Estrangeiro. Tese (Doutorado) - Docência Livre em Direito Internacional, Faculdade de Direito da Universidade de São Paulo, São Paulo, 2008. p. 127.

9 CARRAU, Natalia; VALDOMIR, Sebastián. La incidencia de los Tratados de Protección de Inversiones en el Mercosur. Montevideo: CEFIR, 
Nos tratados sob análise, os mecanismos de solução de controvérsias mais frequentes são a arbitragem ad hoc no ICSID (89\%), seguido pela jurisdição doméstica do Estado receptor como opção (71\%), tribunal ad hoc conforme Regulamento de Arbitragem da UNCITRAL (63\%), mecanismo complementar do ICSID (39\%) e arbitragem ad hoc (12\%) (ver gráfico 2).

Cabe salientar que o ICSID não é um tribunal internacional permanente, mas uma organização internacional do Grupo Banco Mundial, que conta com uma lista de árbitros e que, para cada caso concreto, é integrado um tribunal com eleição de um árbitro por cada uma das partes e outro pelo Centro. Para que o ICSID entenda em uma controvérsia investidor-Estado, é mister que esta seja de natureza jurídica, tenha relação direta com um investimento entre um Estado parte e um nacional de outro Estado parte, e ter assinado uma cláusula de prorrogação de jurisdição por escrito (artigo 25 da Convenção de Washington). Portanto, "foram os TBI os instrumentos idôneos para que este consentimento ficasse manifesto, sendo que a maioria deles inclui a arbitragem junto ao ICSID como mecanismos para a resolução de disputas." ${ }^{10}$.

Ainda, como se depreende do gráfico 3, unicamente $12 \%$ dos TBIs sob análise estabelecem o requisito de esgotamento prévio dos recursos internos para o acesso à arbitragem internacional, reforçando a especialidade do sistema dentro do Direito Internacional Público.

Gráfico 2 - Mecanismos de solução de controvérsia investidorEstado previstos em TBIs na América do Sul

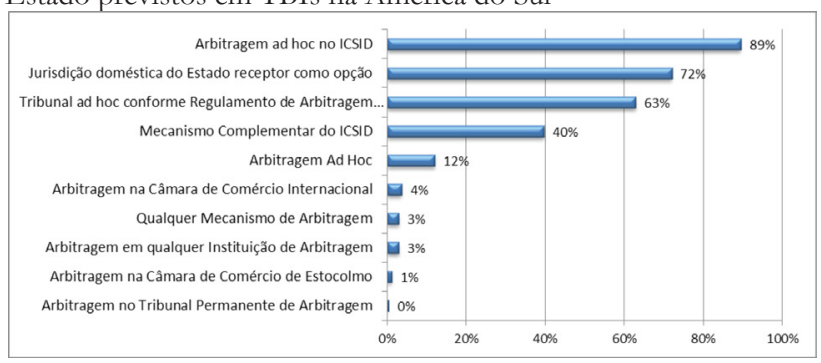

Fonte: Elaboração própria com base nos acordos

GIZ, Somos Mercosur, 2012. p. 49; SALACUSE, Jeswald. The Lam of Investment Treaties. Oxford: Oxford University Press, 2010. p. 127128.

10 COSTANTE, Liliana. Soberanía nacional vs. CIADI: ¿Estados o mercados? Revista de Derecho Público, Buenos Aires, v. 1, n. 2, p. 59-105, set. 2012. Disponível em: <http://www.infojus.gov.ar/_ pdf_revistas/DERECHO_PUBLICO_A1_N2.pdf>. Acesso em: 16 maio 2013. p. 77.
Ainda, como se depreende do gráfico 3, unicamente $12 \%$ dos TBIs sob análise estabelecem o requisito de esgotamento prévio dos recursos internos para o acesso à arbitragem internacional, como propõe a doutrina Calvo $(1868)^{11}$, reforçando a especialidade do sistema dentro do Direito Internacional Público.

Essa doutrina, elaborada em 1868 pelo jurista argentino Carlos Calvo e acolhida em várias constituições latino-americanas, fundamenta-se nos princípios de igualdade soberana, não intervenção e tratamento igualitário entre nacionais e estrangeiros. Os Estados, como soberanos, têm direito a determinar livremente suas políticas internas e externas, sem ingerência estrangeira e, dado que os estrangeiros têm iguais direitos que os nacionais, eles devem esgotar todos os recursos da jurisdição doméstica sem pedir a proteção e/ou intervenção diplomática do Estado de sua nacionalidade ${ }^{12}$.

Ainda que previsto, pode-se elidir pelo jogo da cláusula da nação mais favorecida. Por esta via, o investidor tem acesso ao melhor tratamento que o Estado outorgue em outro acordo, nesse caso, passagem direta à jurisdição arbitral internacional ${ }^{13}$ A jurisprudência, pela primeira vez, o acolhe no caso Maffezini (ICSID caso número ARB $/ 97 / 7)^{14}$.

Nesse caso, o demandante submete a controvérsia com base no tratado de proteção de investimentos entre a Argentina e a Espanha cujo artigo X item 3 estabele-

11 HERZ, Mariana. Régimen argentino de promoción y protección de inversiones en los albores del nuevo milenio: de los tratados bilaterales, Mercosur mediante, al Alca y la OMC. Revista Electrónica de Estudios Internacionales, Madrid, n. 7, dez. 2003. Disponível em: < http://www.reei.org/index.php/revista/num7/archivos/M. Herz(reei7).pdf $>$. Acesso em: 16 maio 2013. p. 13; FERNANDEZ, José. Controvérsias entre Estados e investidores transnacionais: reflexões sobre o acúmulo de casos contra a República Argentina. Revista Tempo do mundo, Brasília, v. 5, n. 1, p. 45-87, abr. 2013. Disponível em: <http://www.ipea.gov.br/portal/images/stories/PDFs/ rtm/140903_rtmv5_n1_port_cap2.pdf > Acesso em: 12 nov. 2014.

12 TAMBURINI, Francesco. Historia y Destino de la Doctrina Calvo: ¿Actualidad u obsolescencia del pensamiento de Carlos Calvo? Revista de estudios histórico-jurídicos, Valapaiso, n. 24, p. 81-101, 2002. Disponível em: <http://www.rehj.cl/index.php/rehj/article/ view/363/343>. Acesso em: 23 jan. 2015. p. 82.

13 BANIFATEMI, Yas. The emerging jurisprudence on the Most-Favored-Nation Treatment in investment arbitration. In: BJORKLUND, Andrea et al. (Ed.). Investment Treaty Law. Current Issues III - Remedies in International Investment Law: Emerging Jurisprudence of International Investment Law. Londres: BIICL, 2009. p. 241-273.

14 MONEBHURRUN, Nitish. Crônicas do Direito Internacional dos Investimentos. Revista de Direito Internacional, Brasília, v. 11, n. 1, p. 10-18, 2014. p. 17-18. 
ce que acionar a arbitragem internacional é possível: a) quando no prazo de dezoito meses não há sentença na jurisdição doméstica; b) quando há decisão, mas a controvérsia subsiste; ou, c) por acordo das partes. Em função da cláusula da nação mais favorecida, o demandante solicita a aplicação das disposições mais favoráveis do tratado entre a Espanha e o Chile. Esse último estabelece que, depois de tentar alcançar uma solução amigável no prazo de seis meses, a jurisdição doméstica é uma opção para o investidor, juntamente à jurisdição arbitral internacional (artigo 10).

Ao lado oposto, encontra-se o caso Plama Consortium contra Bulgária (ICSID caso número ARB/03/24), no qual o tribunal arbitral entende que a cláusula da nação mais favorecida é aplicável unicamente às questões de fundo relativas aos mecanismos de solução de controvérsias e não às processuais.

Gráfico 3 - TBIs na América do Sul que incluem a obrigação de prévio esgotamento dos recursos internos

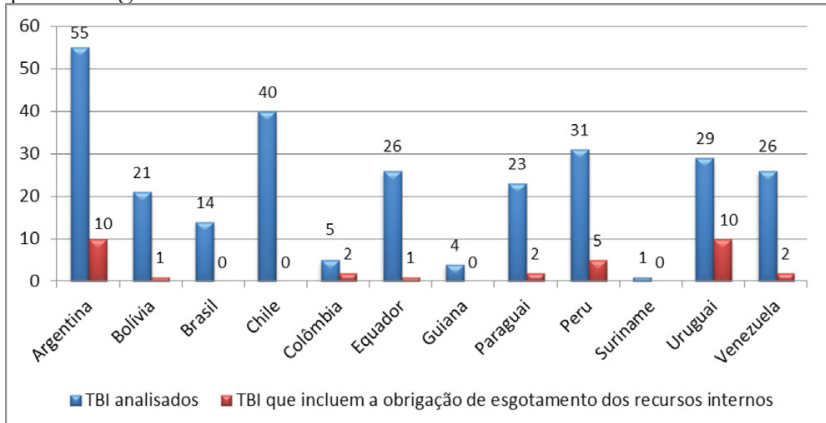

Fonte: Elaboração própria com base no texto dos TBIs

No primeiro decênio do século XXI, o grande número de demandas contra Estados da região, notadamente aquelas com fulcro em nova legislação doméstica relativa a setores econômicos sensíveis como petróleo, gás e mineração, energia elétrica, águas e saneamento; bem como as exorbitantes indenizações reclamadas; o questionamento à imparcialidade dos árbitros nos mecanismos tradicionais de solução de controvérsia investidor-Estado e a inexistência de prova de relação direta entre investimento estrangeiro direto e $\mathrm{TBIs}^{15}$ geraram rupturas na quase monolítica posição do continente durante o decênio anterior. Os diferentes caminhos encetados pelos Estados serão analisados no seguinte ponto.

15 BAKER, Paul. Who Enters Into Bilateral Investment Treaties and Do They Have an Impact on Foreign Direct Investment? Disponível em: $<$ https://editorialexpress.com/cgi-bin/conference/download. cgi?db_name=SAEe2012_Job_Market\&paper_id=49>. Acesso em: 23 jan. 2015.

\section{As três posições na América do Sul}

\subsection{Aspectos preliminares}

Para o estudo da situação atual dos Estados sul-americanos, este trabalho parte da construção de uma tipologia de Estados segundo sua posição com referência ao sistema TBIs-ICSID. Este pode ser analisado como um regime internacional ao conformar uma área específica do sistema internacional em cujo âmbito são gerados acordos formais e informais entre diferentes atores que os compõem. Nesse sentido, na esteira de Krasner, trata-se de um "conjunto implícito ou explícito de princípios, normas, regras e procedimentos de tomada de decisão, sobre os quais as expectativas dos distintos atores convergem em uma área determinada das relações internacionais ${ }^{16}$."

Atualmente, em função dos princípios de igualdade soberana, não intervenção e livre determinação dos povos consagrados na Carta das Nações Unidas e na Declaração 2625, a entrada, permanência ou saída de um regime internacional é uma decisão de cada Estado. Portanto, a percepção de reciprocidade de interesses ou relação ganhar-ganhar será um aspecto crucial na tomada de decisões. De fato, é viável a saída de um regime quando os Estados entendem que os custos de permanecer nele são maiores que as alternativas externas. Todavia, a saída do regime é uma opção sempre presente, além das alternativas externas ou custos internos ${ }^{17}$.

Esse regime internacional tem como princípio fundamental a promoção e a proteção de investimentos, princípio do qual emanam normas gerais que regulam o comportamento dos atores (Estados e investidores), como a prorrogação de jurisdição em favor da arbitragem internacional prevista nos TBI, sempre que o investidor veja vulnerados seus direitos. Ainda, uma série de regras, com regulação heterogênea, derivam da anterior norma, são elas: 1) estabelecimento de um período de esfriamento, isto é, um período em que e as partes

16 KRASNER, Stephen. Structural causes and regime consequences: regimes as intervening variables. In: KRASNER, Stephen (Ed.). International regimes. Ithaca: Cornell University Press, 1983. p. 2. 17 KEOHANE, Robert. Después de la hegemonia: Cooperación y discordia en la política económica mundial. Buenos Aires: Grupo Editor Latinoamericano, 1988. p. 137; KEOHANE, Robert. The demand for international regimes. International Organization, Cambridge, n. 36, p. 325-355, 1982. p. 331. 
no conflito tentam resolver suas controvérsias de forma amigável ${ }^{18}$; 2) esgotamento dos recursos internos como uma opção, não como obrigação; 3) não apelação dos laudos; 4) cláusulas de ultratividade, em função das quais as disposições do tratado mantêm sua vigência durante um período determinado subsequente a seu término ${ }^{19}$; 5) cláusula da nação mais favorecida aplicável a qualquer dos anteriores, como regra reconhecida em parte da jurisprudência do ICSID. Enfim, o anteriormente exposto leva a que os Estados emissores de investimento estrangeiro direto vejam garantidos os investimentos de suas empresas nacionais e a que os Estados receptores contem com instrumentos que ofereçam certeza jurídica ao investidor estrangeiro.

Considerando-se o exposto acima, propõe-se uma tipologia de Estados baseada na posição destes relativamente ao sistema TBIs-ICSID: os membros, os externos e os dissidentes, a qual, a seguir, é aplicada aos Estados sul-americanos.

\subsection{Os membros}

No primeiro tipo de Estados, agrupam-se a Argentina, Chile, Colômbia, Guiana, Paraguai, Peru, Suriname e Uruguai. São aqueles que seguem a tendência favorável à assinatura e entrada em vigor de TBIs e subscrição da Convenção de Washington. Até 31 de janeiro de 2015, a Argentina tem 55 TBIs em vigor; Chile, 40; Colômbia, 5; Guiana, 4; Paraguai, 23; Peru, 31; Suriname, 1, e Uruguai, 29.

O caso mais relevante é a Argentina visto que se trata do Estado sul-americano com maior número de TBIs em vigor ${ }^{20}$. Dos 55 acordos, celebrados entre 1990 e 2000, 53 correspondem à presidência de Menem (1989 - 1999). Sua assinatura foi motivada pelo processo privatizador dos serviços públicos; da crença ideológica nas vantagens de uma maior abertura da economia; da tendência internacional à assinatura de TBIs, e da necessidade de contar com instrumentos jurídicos que outorgassem maior segurança jurídica aos investidores

18 Habitualmente o período se estende de três a seis meses a partir da instauração da controvérsia.

19 Conforme o tratado, esse período pode ser de cinco, dez, quinze ou vinte anos.

20 Este trabalho analisa as características da Argentina até 2015 inclusive, dado o recente início do Governo do Presidente Mauricio Macri, em 10 de dezembro de 2015. estrangeiros ${ }^{21}$. É por conta desse último ponto que $82 \%$ dos TBIs em vigor não exigem o prévio esgotamento dos recursos internos.

No entanto, são principalmente as empresas concessionárias de serviços públicos privatizados as que ajuízam ação contra o Estado ao se verem afetadas pelas medidas tomadas a partir de dezembro de 2001 para paliar a crise econômica e social ${ }^{22}$. Destaca-se a Lei de Emergência Pública e Reforma do Regime Cambiário (Lei 25561) que deixa sem efeito as cláusulas de ajuste em dólares ou outras moedas estrangeiras e as cláusulas sustentadas em parâmetros internacionais, e "pesifica" taxas e preços incluídos em contratos públicos, substituindo os valores expressos em dólares por valores em pesos argentinos ${ }^{23}$. No concernente às controvérsias dirimidas no ICSID, ao final do ano de 2015, a Argentina acumula 53 demandas, 37 ligadas à crise de $2001^{24}$.

Contudo, em 2003 se produz uma mudança estrutural, uma de cujas premissas é o abandono da política de negociação e ratificação de TBIs ${ }^{25}$. Segundo Carlos Bianco $^{26}$, Secretário de Relações Econômicas Internacionais da Chancelaria Argentina, durante o período 2013 - 2015, a mudança de modelo parte de uma posição ideológica sustentada no desenvolvimento industrial e a inclusão social. A despeito de o governo de Fernández de Kirchner (2007 - 2011; 2011 - 2015) ter

21 BELTRAMINO, Ricardo. Promoción de inversiones en los acuerdos de inversiones firmados por Argentina. Buenos Aires: Área de Relaciones Internacionales, FLACSO Argentina, 2010. Disponível em: <http:// rrii.flacso.org.ar/wp-content/uploads/2010/06/FLA_Doc49. pdf>. Acesso em: 24 maio 2014.

22 Exemplo: Azurix Corp. (ICSID número ARB/01/12); CMS Gas Transmission Company (ICSID número ARB/01/8); Compañía de Aguas del Aconquija SA \& Vivendi Universal AS, Continental Casualty Company (ICSID número ARB/97/3); Daimler Financial Services AG (ICSID número ARB/03/9), Gas Natural SDG AS (ICSID número ARB/03/9); National Grid PLC (Regulamento de Arbitragem da UNCITRAL); Suez, Sociedad General de Aguas de Barcelona SA e InterAguas Servicios Integrales del Agua AS (ICSID número ARB/03/17), e Suez, Sociedad General de Aguas de Barcelona SA \& Vivendi AS (ICSID número ARB/03/17).

23 FERNANDEZ, José. Controvérsias entre Estados e investidores transnacionais: reflexões sobre o acúmulo de casos contra a República Argentina. Revista Tempo do mundo, Brasília, v. 5, n. 1, p. 45-87, abr. 2013. Disponível em: < http://www.ipea.gov.br/portal/ images/stories/PDFs/rtm/140903_rtmv5_n1_port_cap2.pdf $>$. Acesso em: 12 nov. 2014.

24 As demandas estão focadas nas cláusulas de tratamento justo e equitativo, tratamento menos favorável e expropriação indireta.

25 Unicamente modifica-se o acordo com o Panamá em 2004 e entra em vigor o acordo com o Senegal em 2010 com a ratificação desse país.

26 Entrevistado em Buenos Aires, 22 de outubro de 2014. 
sido muito crítico dos resultados dos TBIs e ter discutido a possibilidade de denúncia, não se avançou nessa direção. Assim, renovaram-se automaticamente os TBIs em vigor e a Argentina conservou seu status de membro do ICSID.

Seguindo a teoria dos regimes internacionais, a Argentina permanece dentro do regime, porém, com certas restrições. Não obstante, na Câmara de Deputados existem projetos que propõem o abandono do regime, quer seja por denúncia da Convenção de Washington e dos TBIs, quer seja por declaração de nulidade absoluta por transgredir normas constitucionais ou implicar renúncia de soberania ${ }^{27}$.

\subsection{Os externos}

O segundo tipo de Estados inclui aqueles que entendem que os benefícios recebidos depois de incorporação ao regime não são maiores nem iguais aos recebidos antes de sua incorporação e escolhem permanecer fora. Por conseguinte, não assinam, aderem e/ou ratificam a Convenção de Washington nem os TBIs. O Brasil constitui o único exemplo na América do Sul.

$\mathrm{Na}$ década de noventa, seguindo os postulados do consenso de Washington, começa a prática de celebração de TBIs, sendo assinados quatorze entre 1994 e 1999; seis destes acordos chegam ao Congresso Brasileiro. Desde o início, houve oposição parlamentar a sua aprovação até que, em março de 2002, no último ano do governo de Fernando Henrique Cardoso (1995 - 2002), cria-se um Grupo de Trabalho Interministerial que determina que os referidos acordos deverão ser retirados do Congresso ${ }^{28}$.

Os motivos centrais da retirada são, nomeadamente, que os TBIs implicam: comprometer o Estado durante longos períodos; privilegiar mais o investidor estrangeiro que o nacional; possíveis problemas de constitucionalidade, por exemplo, com relação à solução de con-

27 Os projetos são apresentados entre 2006 e 2012 por deputados do Movimento Projeto Sul, Partido Socialista, Soberania Popular, Emancipação e Justiça, Concertação Entrerriana, Sim pela Unidade Popular, GEN, ARI (Movimiento Proyecto Sur, Partido Socialista, Soberania Popular, Emancipación y Justicia, Concertación Entrerriana, Si por la Unidad Popular, GEN, ARI em espanhol).

28 ACTIS, Esteban. Brasil y la promoción de Tratados Bilaterales de Inversión: El fin de la disyuntiva. Latin American Journal of International Affairs, Santiago, v. 6, n. 1, p. 18-33, 2014. Disponível em: < http://www.lajia.net/volumenes/LAJIA\%20vol6\%20n1\%20 Art02.pdf? attredirects=0\&d=1>. Acesso em: 19 nov. 2014 . trovérsias em instâncias internacionais de arbitragem, e riscos na balança de pagamentos, haja vista a livre transferência de capitais ${ }^{29}$.

No entanto, a posição de repúdio à regulação da proteção de investimentos recentemente tem sido questionada pela crescente emissão de investimento estrangeiro direto por parte de empresas brasileiras ${ }^{30}$. Nesse contexto, sob a direção da Secretaria do Comércio Exterior do Ministério de Desenvolvimento, Indústria e Comércio, elabora-se o modelo de tratado de investimentos, o Acordo de Cooperação e Facilitação de Investimentos, como instrumento para oferecer apoio aos investimentos brasileiros no exterior.

O novo modelo de tratado bilateral não tem referências aos mecanismos de solução de controvérsia investidor-Estado, e propõe apenas um mecanismo de prevenção de controvérsias Estado-Estado. São seus alicerces: 1) a existência de Pontos Focais Nacionais ou Ombudsmen em cada Estado, para a prevenção de disputas e facilitação de sua resolução; 2) a conformação de um Comitê Conjunto incumbido de avaliar a controvérsia mediante consultas e negociações entre as partes, como requisito prévio para o início de uma arbitragem internacional Estado-Estado ${ }^{31}$. Destarte, os Acordos de Cooperação e Facilitação de Investimentos resolvem parte dos problemas tradicionalmente concernentes aos TBIs, isto é, mitigam os riscos e as eventuais controvérsias e eliminam as cláusulas draconianas que oferecem maiores vantagens aos investidores estrangeiros frente aos nacionais ${ }^{32}$.

Seis acordos foram assinados ao encerramento do ano de 2015, com os seguintes Estados: Moçambique

29 AZEVEDO, Déborah Bithiah de. Os acordos para a promoção e a proteção recíproca de investimentos assinados pelo Brasil. Brasília: Câmara dos Deputados do Brasil, 2001. Disponível em: <http://www2. camara.leg.br/documentos-e-pesquisa/publicacoes/estnottec/ tema3/pdf/102080.pdf>. Acesso em: 31 maio 2014.

30 MONEBHURRUN, Nitish. Crônicas do Direito Internacional dos Investimentos. Revista de Direito Internacional, Brasília, v. 12, n. 2, p. 64-77, 2014. p. 66; HASTREITER, Michele Alessandra; WINTER, Luis Alexandre Carta. Racionalidade econômica e os acordos bilaterais de investimento. Revista de Direito Internacional, Brasília, v. 12, n. 3, p. 64-77, 2015.

31 Os acordos assinados com o México e Colômbia regulam em texto expresso a possibilidade de submeter a controvérsia a um Tribunal arbitral ad hoc (artigos 19 e 22).

32 ACTIS, Esteban. Brasil frente al orden internacional liberal (2011 - 2013). Los límites de la posición reformista a la luz del régimen internacional de inversiones. Mural Internacional, Rio do Janeiro, v. 6, n. 1, p. 22-34, 2015. p. 29. 
(30 de março de 2015); Angola (1 ${ }^{\circ}$ de abril de 2015); México (26 de maio de 2015); Malaui (25 de junho de 2015); Colômbia (9 de outubro de 2015); Chile (23 de novembro de 2015). Encontram-se em etapa de negociação os acordos com Argélia, Marrocos, Nigéria, Peru, África do Sul e Tunísia ${ }^{33}$.

\subsection{Os dissidentes}

Bolívia $^{34}$, Equador ${ }^{35}$ e Venezuela ${ }^{36}$ são os primeiros Estados na América do Sul a denunciar a Convenção de Washington em $1^{\circ}$ de maio de 2007, 2 de julho de 2009 e 24 de janeiro de 2012, respectivamente ${ }^{37}$, e começando o processo de não renovação ou denúncia dos TBIs em vigor no caso da Bolívia ${ }^{38}$ e do Equador. Este processo pode enquadrar-se no abandono de um regime internacional, o sistema TBIs-ICSID, no entendimento de que os custos de permanecer nele são maiores que as alternativas externas.

O Equador apresenta mudanças institucionais que merecem uma análise especial. O processo de abandono do regime internacional tem início em 2008 com a denúncia de nove TBIs com base nos quais não se tinham registrado investimentos recíprocos, isto é, Cuba, El Salvador, Guatemala, Honduras, Nicarágua, Paraguai, República Dominicana, Romênia e Uruguai ${ }^{39}$. Com a Constituição de 2008 em vigor, unicamente alcança a

33 DIETRICH, Martin. The Brazil-Mozambique and Brazil-Angola Cooperation and Investment Facilitation Agreements (CIFAs): A Descriptive Overview, 2015. Disponível em: <https://www.iisd.org/ itn/2015/05/21/the-brazil-mozambique-and-brazil-angola-cooperation-and-investment-facilitation-agreements-cifas-a-descriptiveoverview/>. Acesso: 10 jun. 2015.

34 A Bolívia é o Estado que mais avançou: 8 dos acordos não são renovados, e em maio de 2013 o país denúncia de forma conjunta os 21 restantes. Por uma análise mais profunda ver:

35 Ao início do processo de denúncia, o Equador tem 26 TBIs em vigor.

36 A Venezuela conta com 27 TBIs, incluindo o acordo com Países Baixos, denunciado.

37 As denúncias são efetivas seis meses após sua notificação (artigo 71 do Convenção de Washington).

38 ORELLANA, Aldo. Bolivia denuncia sus tratados bilaterales de inversión e intenta poner fin al poder de las corporaciones para demandar al país en Tribunales Internacionales. 2014. Disponível em: <http:// justinvestment.org/wp-content/uploads/2014/07/Bolivia-denuncia-sus-Tratados-Bilaterales-de-Inversi $\% \mathrm{C} 3 \% \mathrm{~B} 3 n$-e-intenta-ponerfin-al-poder-de-las-corporaciones-para-demandar-al-pa \%C3\%ADsen-Tribunales-Internacionales1.pdf>. Acesso em: 14 dez. 2014.

39 GUERRA, Gustavo. Las disposiciones legales que desarrollan los preceptos constituciones sobre la inversión privada extranjera en el Ecuador. Foro: Revista de Derecho, Quito, n. 17, p. 31-62, set. 2012. p. 43. última etapa do processo de denúncia o TBI Equador-Finlândia ${ }^{40}$. Contudo, na maioria dos tratados existem cláusulas de ultratividade que determinam que suas disposições se mantenham em vigor por mais cinco, dez ou quinze anos, para aqueles investimentos realizados com antecedência à notificação de término.

Em 2013 é criada a Comissão para a Auditoria Integral Cidadã dos Tratados de Proteção Recíproca de Investimentos e do Sistema de Arbitragem Internacional em Matéria de Investimentos ${ }^{41}$, com o intuito de analisar os TBIs e outros instrumentos internacionais relativos a investimentos que obriguem o Estado, as normas de arbitragem internacional e as demandas contra o Equador.

O especialista em Direito Internacional Público e membro da Comissão para a Auditoria Integral Cidadã, Javier Echaide ${ }^{42}$, explica que os motivos do Equador para tomar esta postura são: 1) a incompatibilidade com disposições da Constituição de 2008, principalmente com relação ao estabelecimento de uma jurisdição distinta da doméstica (artigo 422); 2) a necessidade de avançar com relação à proteção dos direitos da natureza com consagração constitucional (artigo 71 a 74); 3) aspectos conjunturais, tais como as demandas da Ocidental Petroleum Corporation e a Ocidental Exploration and Production Company (ICSID caso número ARB/06/11) e da Chevron Corporation e Texaco Petroleum Company (Corte Permanente de Arbitragem caso número 2007-2); e 4) as afetações indiretas dos casos que se dirimem em jurisdições diferentes, como a problemática do meio ambiente no Lago Agrio vinculada ao caso Chevron.

No que tange às demandas, conforme as declarações de Osvaldo Guglielmino, ex-procurador do Estado da Argentina e membro da Comissão para a Auditoria Integral Cidadã, ao jornal equatoriano El Telégrafo datadas de 7 de agosto de 2014, o Equador recebeu de-

40 O processo atual é: 1) Ofício da Presidência encaminhado à Corte Constitucional solicitando pronunciamento sobre a denúncia; 2) Sentença da Corte Constitucional; 3) Ofício da Presidência à Assembleia Nacional solicitando a denúncia; 4) Relatório da Comissão especializada permanente de soberania, integração, relações internacionais e segurança integral da Assembleia Nacional; 5) Resolução da Plenária da Assembleia Nacional; 6) Notificação escrita encaminhada à contraparte.

41 Comisión para la Auditoría Integral Ciudadana de los Tratados de Protección Reciproca de Inversiones y del Sistema de Arbitraje Internacional en Materia de Inversiones em espanhol.

42 Entrevistado em Buenos Aires, em 16 de outubro de 2014. 
mandas reclamando uma quantia total de cerca de 19,5 bilhões de dólares, mas foi condenado a pagar apenas 2,5. Ainda, a título de honorários advocatícios pagaram-se 118 milhões de dólares, e 12 milhões por conta de gastos dos tribunais arbitrais ${ }^{43}$.

Nesse contexto, desde 2009 o Equador impulsiona a criação de uma instituição regional de solução de controvérsias em matéria de investimentos, o Centro de Solução de Controvérsias em Matéria de Investimentos da UNASUL. Embora este foro implique realizar uma prorrogação de jurisdição em seu favor, ela está contemplada dentro da Constituição equatoriana (2008) ao excetuar-se da regra:

\begin{abstract}
Os tratados e instrumentos internacionais que estabeleçam a solução de controvérsias entre Estados e cidadãos na América Latina por instâncias arbitrais regionais ou por órgãos jurisdicionais de designação dos países signatários. (artigo 422) ${ }^{44}$.
\end{abstract}

Também, no texto resultante da reunião de agosto de 2013, relativa ao Acordo constitutivo do Centro de Solução de Controvérsias em Matéria de Investimentos da UNASUL a que tivemos acesso, o artigo 10 estabelece a faculdade do Estado de exigir o esgotamento prévio da jurisdição doméstica para submeter uma controvérsia investidor-Estado a conciliação ou arbitragem. A faculdade deve ser exercida no momento de outorgar a prorrogação de jurisdição em favor do Centro, contida em um tratado, contrato, declaração específica ou outros atos jurídi$\cos (\operatorname{artigo~} 5)^{45}$. Embora não seja isto um regresso total à doutrina Calvo, percebe-se um claro respeito à soberania estatal ao outorgar ao Estado tal possibilidade de eleição.

\section{Considerações finais}

Ao longo deste trabalho, tentamos contribuir para o conhecimento dos modelos de solução de controvérsias

43 CAITISA arroja sus primeras observaciones a los TBI. Disponível em: <http://www.telegrafo.com.ec/politica/item/caitisa-arrojasus-primeras-observaciones-a-los-tbi.html> . Acesso em: 16 mar. 2015. 44 O artigo 151 da Constituição venezuelana (1999) contém uma disposição semelhante que restringe tais controvérsias à jurisdição doméstica, a qual é ampliada pela Lei de investimentos estrangeiros (2014) aos mecanismos de solução de controvérsias previstos no âmbito dos processos de integração da América Latina e o Caribe. A Constituição boliviana (2009) também prevê que todo investimento estrangeiro estará submetido à jurisdição doméstica.

45 Esses instrumentos podem ser: tratados bilaterais de investimento, capítulos dedicados a investimentos em acordos multilaterais ou tratados de livre comércio, leis internas de investimento, contratos entre investidores e Estados, dentre outros.
investidor-Estado previstos nos TBIs vigentes nos Estados sul-americanos, ressalvadas as exceções da Bolívia e do Equador que iniciaram processos de término dos acordos em vigor, e do Brasil, que não ratificou nenhum dos TBIs assinados e começou a celebrar um novo modelo de acordo bilateral, os Acordos de Cooperação e Facilitação de Investimentos.

Como primeiro objetivo de pesquisa, colocou-se a sistematização dos TBIs vigentes nos Estados sul-americanos e sua categorização conforme os sistemas de solução de controvérsias investidor-Estado propostos. Em relação aos TBIs analisados, o mecanismo de solução de controvérsias mais frequente é a arbitragem ad hoc no ICSID, seguido da jurisdição doméstica do Estado receptor como opção, e dos tribunais ad hoc segundo o Regulamento de Arbitragem da UNCITRAL, dispensando o requisito de esgotamento dos recursos internos nos $88 \%$ dos casos. Quanto aos Acordos de Cooperação e Facilitação de Investimentos, a solução de controvérsias investidor-Estado não está prevista na articulação, debruçando-se, exclusivamente, sobre os meios alternativos de resolução de conflitos e das controvérsias Estado-Estado.

Como segundo objetivo de pesquisa, colocou-se o exame das posições dos Estados sul-americanos a respeito do sistema TBIs-ICSID. Nesse sentido, construiu-se uma tipologia de Estados conforme sua posição a respeito do sistema, dividindo-os em três tipos: os membros (Argentina, Chile, Colômbia, Guiana, Paraguai, Peru, Suriname e Uruguai), os externos (Brasil) e os dissidentes (Bolívia, Equador e Venezuela).

O pertencimento a cada tipo deve-se, basicamente, a dois fatores. Em primeiro lugar, encontram-se os aspectos conjunturais, especialmente a experiência nos mecanismos de solução de controvérsias investidor-Estado, particularmente o ICSID, isto é, número de demandas registradas contra o Estado e o montante indenizatório reclamado por demanda. Nesse ponto marcam-se claras diferenças entre Estados como o Equador, com baixo número de demandas que reclamam quantias milionárias, e a Argentina, que acumula o maior número de demandas na América do Sul e no mundo, porém, de baixos montantes em nível individual.

Em segundo lugar, os Estados sob análise também seguem variáveis vinculadas a seu Direito interno na hora de decidir pertencer ou não ao regime. Destaca-se o caso do Equador e da Venezuela, cujas constituições estabe- 
lecem como obrigatória a jurisdição doméstica para as controvérsias investidor-Estado, com exceção, nos dois últimos casos, dos mecanismos previstos em processos de integração latino-americanos e caribenhos. No caso do Brasil, historicamente entendeu que as normas do sistema TBIs-ICSID ferem disposições constitucionais.

A ausência de uma voz comum na região tem levado a que as políticas individuais, apesar de aparentemente sólidas em nível nacional, colidem no contexto regional. O projeto equatoriano de criação de um Centro de Solução de Controvérsias em Matéria de Investimentos da UNASUL ${ }^{46}$ é um passo para neutralizar a fragmentação de estratégias em nível regional e procurar a construção de um sistema legal de solução de controvérsias investidor-Estado como regime internacional próprio, alicerçado em lógicas regionais. Ainda, a iniciativa venezuelana a respeito do Observatório do Sul sobre Investimentos e Transnacionais ${ }^{47}$, no futuro, pode ajudar a construir uma posição regional e a capitalizar experiências individuais.

No entanto, seria desejável que este processo de construção de um sistema legal regional interpelasse os Estados sul-americanos a discutirem publicamente sobre outros aspectos vinculados aos TBIs, tais como a cláusula da nação mais favorecida, as cláusulas de ultratividade, o tratamento justo e equitativo, o conceito de expropriação indireta, o esgotamento prévio dos recursos internos, e o próprio conceito de investimento, dentre outros. Desta forma, contar-se-ia com bases sólidas para a negociação de futuros acordos ou a renegociação daqueles vigentes contemplando os interesses da região, notadamente o modelo de desenvolvimento no qual se deseje apostar.

\section{REFERÊNCIAS BIBLIOGRÁFICAS}

ACTIS, Esteban. Brasil frente al orden internacional liberal (2011 - 2013). Los límites de la posición reformista a la luz del régimen internacional de inversiones. $M u$ ral Internacional, Rio do Janeiro, v. 6, n. 1, p. 22-34, 2015.

46 Depois de quatro anos, o Grupo de Trabalho de Especialistas de Alto Nível concluiu a elaboração do texto do acordo em novembro de 2014, mas continua o debate no nível político.

47 O texto na íntegra da declaração da II Conferência Ministerial de Estados Afetados por Interesses Transnacionais, que cria o Observatório do Sul, está disponível em: http://rcci.net/globalizacion/2014/fg1896.htm.
ACTIS, Esteban. Brasil y la promoción de Tratados Bilaterales de Inversión: El fin de la disyuntiva. Latin American Journal of International Affairs, Santiago, v. 6, n. 1, p. 18-33, 2014,. Disponível em: <http://www. lajia.net/volumenes/LAJIA\%20vol6\%20n1\%20Art02. pdf ?attredirects $=0 \& d=1>$. Acesso em: 19 nov. 2014.

AZEVEDO, Déborah Bithiah de. Os acordos para a promoção e a proteção recíproca de investimentos assinados pelo Brasil. Brasília: Câmara dos Deputados do Brasil, 2001. Disponível em: <http://www2.camara.leg.br/documentos-e-pesquisa/publicacoes/estnottec/tema3/ pdf/102080.pdf>. Acesso em: 31 maio 2014.

BAKER, Paul. Who Enters Into Bilateral Investment Treaties and Do They Have an Impact on Foreign Direct Investment? Disponível em: <https://editorialexpress.com/cgibin/conference/download.cgi?db_name=SAEe2012_ Job_Market\&paper_id=49>. Acesso em: 23 jan. 2015.

BANIFATEMI, Yas. The emerging jurisprudence on the Most-Favored-Nation Treatment in investment arbitration. In: BJORKLUND, Andrea et al. (Ed.). Investment Treaty Law. Current Issues III - Remedies in International Investment Law: Emerging Jurisprudence of International Investment Law. Londres: BIICL, 2009. p. 241-273.

BeLtRAMINO, Ricardo. Promoción de inversiones en los acuerdos de inversiones firmados por Argentina. Buenos Aires: Área de Relaciones Internacionales, FLACSO Argentina. 2010. Disponível em: < http://rrii.flacso.org.ar/wpcontent/uploads/2010/06/FLA_Doc49.pdf >. Acesso em: 24 maio 2014.

BOEGLIN, Nicolás. Ecuadory el CLADI: nuevo pulso con posibles repercusiones. 2012. Disponível em: <http:// alainet.org/active/58693 >. Acesso: 23 jan. 2015

BOHOSLAVSKY, Juan Pablo. Tratados de protección de las inversiones e implicaciones para la formulación de políticas públicas (especial referencia a los servicios de agua potable y saneamiento). Santiago: Comisión Económica para América Latina y el Caribe (CEPAL), 2010.

CARRAU, Natalia; VALDOMIR, Sebastián. La incidencia de los Tratados de Protección de Inversiones en el Mercosur. Montevideo: CEFIR, GIZ, Somos Mercosur, 2012.

COSTA, José Augusto Fontoura. Direito Internacional do Investimento Estrangeiro. 2008. Tese (Doutorado) Docência Livre em Direito Internacional, Faculdade de Direito da Universidade de São Paulo, São Paulo, 2008. 
COSTANTE, Liliana. Soberanía nacional vs. CIADI: ¿Estados o mercados? Revista de Derecho Público, Buenos Aires, v. 1, n. 2, p. 59-105, set. 2012. Disponível em: <http://www.infojus.gov.ar/_pdf_revistas/DERECHO_PUBLICO_A1_N2.pdf $>$. Acesso em: 16 maio 2013.

DIETRICH, Martin. The Brazil-Mozambique and Bra$z_{i}$ il-Angola Cooperation and Investment Facilitation Agreements (CIFAs): A Descriptive Overview, 2015. Disponível em: <https://www.iisd.org/itn/2015/05/21/the-brazil-mozambique-and-brazil-angola-cooperation-andinvestment-facilitation-agreements-cifas-a-descriptiveoverview/>. Acesso em: 10 jun. 2015.

FACH, Katia. Latin America and ICSID: David versus Goliath? Disponível em: <http://ssrn.com/abstract $=1708325>$. Acesso em: 14 dez. 2014 .

FERNANDEZ, José. Controvérsias entre Estados e investidores transnacionais: reflexoes sobre o acúmulo de casos contra a República Argentina. Revista Tempo do mundo, Brasília, v. 5, n. 1, p. 45-87, abr. 2013. Disponível em: <http://www.ipea.gov.br/portal/images/stories/ PDFs/rtm/140903_rtmv5_n1_port_cap2.pdf $>$. Acesso em: 12 nov. 2014.

GUERRA, Gustavo. Las disposiciones legales que desarrollan los preceptos constituciones sobre la inversión privada extranjera en el Ecuador. Foro: Revista de Derecho, Quito, n. 17, p. 31-62, set. 2012.

HASTREITER, Michele Alessandra; WINTER, Luís Alexandre Carta. Racionalidade econômica e os acordos bilaterais de investimento. Revista de Direito Internacional, Brasília, v. 12, n. 3, p. 64-77, 2015.

HERZ, Mariana. Régimen argentino de promoción y protección de inversiones en los albores del nuevo milenio: de los tratados bilaterales, Mercosur mediante, al Alca y la OMC. Revista Electrónica de Estudios Internacionales, Madrid, n. 7, dez. 2003. Disponível em: < http:// www.reei.org/index.php/revista/num $7 / \operatorname{archivos/M}$. Herz(reei7).pdf>. Acesso em: 16 maio 2013.

KEOHANE, Robert. Después de la hegemonía. Cooperación y discordia en la política económica mundial. Buenos Aires: Grupo Editor Latinoamericano, 1988.

KEOHANE, Robert. The demand for international regimes. International Organization, Cambridge, n. 36, p. 325-355, 1982.
KRASNER, Stephen. Structural causes and regime consequences: regimes as intervening variables. In: KRASNER, Stephen (Ed.). International regimes. Ithaca: Cornell University Press, 1983.

LIMA, Gabriela Garcia Batista. Conceitos de relações internacionais e teoria do direito diante dos efeitos pluralistas da globalização: governança global, regimes jurídicos, direito reflexivo, pluralismo jurídico, corregulação e autorregulação. Revista de Direito Internacional, Brasília, v. 11, n. 1, p. 215-228, 2014.

MONEBHURRUN, Nitish. Crônicas do Direito Internacional dos Investimentos. Revista de Direito Internacional, Brasília, v. 12, n. 2, p. 64-77, 2014.

MONEBHURRUN, Nitish. Crônicas do Direito Internacional dos Investimentos. Revista de Direito Internacional, Brasília, v. 11, n. 1, p. 10-18, 2014.

NASSER, Salem Hikmat. Direito Global em pedaços: fragmentação, regimes e pluralismo. Revista de Direito Internacional, Brasília, v. 12, n. 2, p. 98-126, 2015.

ORGANIZAÇÃO DAS NAÇÕES UNIDAS. Fragmentación del Derecho Internacional: dificultades derivadas de la diversificación y expansión del Derecho Internacional. Anuario de la Comisión de Derecho Internacional, $58^{a}$ periodo de sesiones, p. 192-202, Nova Iorque. Disponível em: <http://legal.un.org/docs/ index.asp?path=../ilc/reports/2006/spanish/chp12. pdf\&lang=EFSRAC\&referer=http://legal.un.org/ilc/ reports/2006/>. Acesso em: 28 fev. 2016.

ORELLANA, Aldo. Bolivia denuncia sus tratados bilaterales de inversión e intenta poner fin al poder de las corporaciones para demandar al país en Tribunales Internacionales. 2014. Disponível em: <http://justinvestment.org/ wp-content/uploads/2014/07/Bolivia-denuncia-susTratados-Bilaterales-de-Inversi $\%$ C3\%B3n-e-intentaponer-fin-al-poder-de-las-corporaciones-para-demandar-al-pa \%C3\%ADs-en-Tribunales-Internacionales1. pdf>. Acesso em: 14 dez. 2014.

RUGGIE, John. International Responses to Technology: Concepts and Trends. International Organization, Cambridge, v. 3, n. 29, p. 557-583, 1975. Disponível em: <http://www.jstor.org/stable/2706342>. Acesso em: 12 out. 2015 .

SALACUSE, Jeswald. The Law of Investment Treaties. Oxford: Oxford University Press, 2010. 
SCHREUER, Christoph. The ICSID Convention: A Commentary. 2. ed. Cambridge: Cambridge University Press, 2009.

TAMBURINI, Francesco. Historia y Destino de la Doc- trina Calvo: ¿Actualidad u obsolescencia del pensamiento de Carlos Calvo? Revista de estudios histórico-jurídicos, Valapaiso, n. 24, p. 81-101, 2002. Disponível em: < http:/ / www.rehj.cl/index.php/rehj/article/view/363/343>. Acesso em: 23 jan. 2015.

\section{Apêndice A - Casos arbitrais consultados}

\begin{tabular}{|l|l|l|l|}
$\begin{array}{l}\text { Estado } \\
(\text { demandado })\end{array}$ & Inversor (requerente) & Foro arbitral & Número \\
\hline Argentina & Azurix Corp. & ICSID & ARB/01/12 \\
\hline Argentina & CMS Gas Transmission Company & ICSID & ARB/01/8 \\
\hline Argentina & $\begin{array}{l}\text { Compañía de Aguas del Aconquija SA \& Vivendi } \\
\text { Universal SA }\end{array}$ & ICSID & ARB $/ 97 / 3$ \\
\hline Argentina & Continental Casualty Company & ICSID & ARB/03/9 \\
\hline Argentina & Daimler Financial Services AG & ICSID & ARB/05/1 \\
\hline Argentina & Gas Natural SDG SA & ICSID & ARB/03/10 \\
\hline Argentina & National Grid PLC & Arbitragem ad hoc (Regulamento de & Arbitragem da UNCITRAL) \\
\hline Argentina & $\begin{array}{l}\text { Suez, Sociedad General de Aguas de Barcelona SA e } \\
\text { InterAguas Servicios Integrales del Agua SA }\end{array}$ & ICSID & ARB $/ 03 / 17$ \\
\hline Argentina & $\begin{array}{l}\text { Suez, Sociedad General de Aguas de Barcelona SA \& } \\
\text { Vivendi SA }\end{array}$ & ICSID & ARB $/ 03 / 19$ \\
\hline Bulgária & Plama Consortium & ICSID & ARB/03/24 \\
\hline Equador & Chevron Corporation \& Texaco Petroleum Company & TPA & $2007-2$ \\
\hline Equador & $\begin{array}{l}\text { Occidental Petroleum Corporation \& Occidental } \\
\text { Exploration and Production Company }\end{array}$ & ICSID & ARB $/ 06 / 11$ \\
\hline Espanha & Agustín Maffezini & ICSID & ARB/97/7 \\
\hline
\end{tabular}


Para publicar na Revista de Direito Internacional, acesse o endereço eletrônico www.rdi.uniceub.br ou www.brazilianjournal.org.

Observe as normas de publicação, para facilitar e agilizar o trabalho de edição. 